Prospective Evaluation

\title{
Dural Sac Cross-Sectional Area Does Not Correlate with Efficacy of Percutaneous Adhesiolysis in Single Level Lumbar Spinal Stenosis
}

\author{
Chan Hong Park, MD, PhD'1, Sang Ho Lee, MD, PhD'1, and Jin Young Jung, MD, PhD²
}

From: ${ }^{2}$ Daegu Wooridul Spine Hospital Daegu, South Korea 2Department of Anesthesiology and Pain Medicine, Daegu Catholic University Medical Center, Daegu, South Korea

Address correspondence: Dr. Chan Hong Park 648 Gugchaebosang-ro, Junggu, Daegu, South Korea, 700732

E-mail: magaryı@hanmail.net

Disclaimer: There was no external funding in the preparation of this manuscript.

Conflict of interest: None.

Manuscript received: 02/01/2011 Revised manuscript received: $03 / 21 / 2011$ Accepted for publication: 04/15/2011

Free full manuscript: www.painphysicianjournal.com
Background: Spinal stenosis is a narrowing of the spinal canal, which causes mechanical compression of spinal nerve roots. The compression of these nerve roots can cause low back pain and/or leg pain, as well as neurogenic claudication.

Lumbar epidural steroid injections have commonly been used in patients with lumbar spinal stenosis (LSS). In cases that are refractory to epidural steroid injections, percutaneous epidural adhesiolysis has been used.

Objective: The aim of our study is to determine the relationship between the severity of spinal stenosis and the participants' response to adhesiolysis, and to evaluate the mid-term effectiveness of adhesiolysis.

Study Design: A prospective observational study.

Methods: Sixty-six patients with degenerative LSS were enrolled in this prospective study. All participants underwent lumbar spine magnetic resonance imaging (MRI). The cross-sectional area of the dural sac was measured on the transverse angled sections through the central part of the disc on conventional MR images. All percutaneous adhesiolyses were performed in the operating room. One hour following the procedure, $6 \mathrm{~mL}$ of $8 \%$ sodium chloride solution was infused during 30 minutes in the recovery room while the patient underwent monitoring. Outcome measures were obtained using the 5-point patient satisfaction scale at 2 weeks and 6 months post-treatment. To evaluate outcome predictors, we divided the participants into 2 groups according to their response to treatment.

Limitations: Secondary outcomes were not measured and the study did not include a long-term follow-up period.

Results: Improvement (including reports of slightly improved, much improved, and no pain) was observed in 49 participants $(74.2 \%)$ at 2 weeks and 45 participants (66.7\%) at 6 months after the procedure. The dural sac cross-sectional area (DSCSA) did not differ between participants who reported improvement and those who did not. There was no statistically significant correlation between pain relief and DSCSA, age, or participant sex.

Conclusion: Percutaneous adhesiolysis was shown to be effective for the treatment of LSS, with mid-term result, without affecting DSCSA.

Key words: Low back pain, lumbar spinal stenosis, failed back surgery syndrome, dural sac, interventional techniques, epidural injection, percutaneous adhesiolysis.

Pain Physician 2011; 14:377-382 
umbar spinal stenosis (LSS) is a common degenerative disease. Spinal stenosis can be defined as a narrowing of the spinal canal by a combination of bone and soft tissues, which causes mechanical compression of spinal nerve roots. The compression of these nerve roots can be asymptomatic, but it can also become symptomatic, resulting in weakness, reflex alterations, gait disturbances, bowel or bladder dysfunction, motor and sensory changes, radicular pain or atypical leg pain, and neurogenic claudication $(1,2)$. Stenosis may occur in any spinal canal region including the central, lateral recess, foraminal, and extraforaminal regions (1,3-6).

Treatment modalities for LSS vary and include medication, exercise, interventional techniques, and surgery (6-25). Lumbar epidural steroid injections have commonly been used in patients with LSS $(2,6,8-11,15-$ $17,21-25,8-10)$. However, the effects of this treatment are variable $(6,8-10,23)$. One study reported that fluoroscopically guided caudal epidural steroid injection is effective for the management of LSS for up to 2 years (24). Botwin et al (25) reported that $75 \%$ of patients had a successful long-term outcome, reporting at least a $>50 \%$ reduction between preinjection and postinjection pain scores, with an average of 1.9 injections per patient. Manchikanti et al $(9,10)$ reported, in a randomized, double-blind study, active long-term improvement in approximately $50 \%$ of participants receiving local anesthetic with or without steroids.

Percutaneous epidural adhesiolysis has been used in conditions of refractory chronic low back pain or following failed back surgery syndrome $(6,8,12$ $14,18,19)$. The goal of adhesiolysis is to ameliorate aberrant adhesion and to deliver medication to the targeted site. In patients with spinal stenosis, percutaneous adhesiolysis provides the combined advantages of local anesthetics delivery, steroids administration, and hypertonic sodium chloride solutions injection by means of targeted delivery $(18,19)$. Manchikanti et al (18) reported significant pain relief ( $\geq 50 \%$ ) in $76 \%$ of the patients with LSS at one-year follow-up after adhesiolysis.

The correlation between the degree of LSS and clinical symptoms has been reported $(26,27)$. The degree of radiographic LSS has not been found to correlate with clinical symptoms or Oswestry Disability Index (ODI) percentage scores $(3,26)$. In searching the PubMed database, we found only one article that addressed the correlation of spinal canal dimensions with the efficacy of epidural steroid injection in spinal steno- sis (27). In this study, the authors reported that spinal canal dimension is not predictive of the success or failure of epidural steroid injection in patients with spinal stenosis (27).

To our knowledge, there has been no report regarding a correlation between response to percutaneous adhesiolysis and degree of spinal stenosis. The aim of the current study is to determine the relationship between the severity of spinal stenosis and an individual's response to adhesiolysis and mid-term outcome.

\section{Methods}

\section{Study Design}

Sixty-six patients with degenerative LSS were enrolled in this study. The diagnosis of LSS was made based on clinical symptoms, neurological examinations, and imaging studies that included plain radiography, as well as magnetic resonance imaging (MRI) of the lumbar spine. All participants obtained Institutional Review Board (IRB) approval and signed an informed consent form.

\section{Participants}

The inclusion criteria for the current study were as follows: 1) all participants had the typical symptoms of LSS; 2) had a diagnosis of lumbar central stenosis with back or leg pain; 3) had clear evidence of LSS (in particular central canal stenosis) on cross-sectional images from spinal MRI confirmed by radiologic reports. The exclusion criteria were: 1) an unclear description of symptoms; 2) foraminal or extraforaminal stenosis on cross-sectional images; 3) spondylolisthesis, previous back surgery; 4) multiple level LSS.

All participants underwent lumbar spine MRI (Achieva 1.5T, Philips, The Netherlands). T2 axial images were obtained. The image matrix was 296 X 188 pixels, the field of view was $16 \mathrm{~cm}$, the section thickness was $4 \mathrm{~mm}$, the intersection gap was $0.44 \mathrm{~mm}$ and the echo train lengths were 25 for T2 weighted imaging. The cross-sectional area of the dural sac was measured on the transverse angled sections through the central part of the disc on conventional MR images at the lesion level. The dural sac cross-sectional area (DSCSA) was calculated (total pixels per cross-section $\mathrm{X}$ scan correction factor). Two radiologists blind to the participants' clinical symptoms and radiologic reports scored the images.

All percutaneous adhesiolysis procedures were 
performed in the operating room. With the patient in the prone position, the needle insertion site was prepared with Betadine and draped. An RK epidural needle was introduced into the caudal epidural space under fluoroscopic guidance. Once the needle placement was confirmed to be in the epidural space, a lumbar epidurogram was performed using approximately $5 \mathrm{~mL}$ of contrast agent (Omnipaque 300, GE Healthcare, UK). The identification of the filling defects was attained by examining the contrast agent flow. We confirmed that there was no intravascular or subarachnoid placement of the needle; if such malpositioning occurred, the needle was repositioned. After the appropriate confirmation of epidurography, a Racz catheter was advanced through the RK needle to the area of the filling defect or the site of pathology, as determined by MRI. Adhesiolysis was then carried out, and the final positioning was achieved in the epidural space and into the lateral and ventral epidural space. Following the satisfactory positioning of the catheter, at least $3 \mathrm{~mL}$ of contrast agent was injected. If there was no subarachnoid, intravascular, or other extra-epidural filling and satisfactory filling was obtained with the epidural and targeted regions, $5 \mathrm{~mL}$ of $0.2 \%$ preservative free ropivacaine (Naropine, Astrazeneca, UK) containing 1500 units of hyaluronidase (H-rase, Kuhnil, South Korea) and 40 mg of triamcinolone was injected.

One hour following the procedure, $6 \mathrm{~mL}$ of $8 \%$ sodium chloride solution was intravenously infused over 30 minutes in the recovery room under monitoring. The intravenous line and epidural catheter were removed and the patient was discharged if all parameters were satisfactory. The first follow-up was performed 2 weeks following the procedure. During these two weeks, all participants received nonsteroidal anti-inflammatory drugs (NSAIDs) and muscle relaxants. In addition, participants who were nonresponsive to this therapy were given opioid or non-opioid analgesics after the first follow-up. Only nonresponsive patients received additional procedures that included caudal, interlaminar, or transforaminal epidural steroid injections.

Outcome measurements were obtained using the 5-point patient satisfaction scale (no pain, much improved, slightly improved, no change, aggravated pain) to assess the response to the procedure after 2 weeks and 6 months. To evaluate correlations between pain reduction and age, sex, and DSCSA, we divided the participants into 2 groups according to their response to the procedure: these groups reported improvement
Table 1 Patients characteristics

\begin{tabular}{|c|c|c|}
\hline & Frequency & $\%$ \\
\hline \multicolumn{3}{|l|}{ Levels } \\
\hline $\mathrm{L} 3 / 4$ & 1 & 1.5 \\
\hline $\mathrm{L} 4 / 5$ & 55 & 83.4 \\
\hline $\mathrm{L} 5 / \mathrm{S} 1$ & 10 & 15.2 \\
\hline \multicolumn{3}{|l|}{ Site } \\
\hline Right & 27 & 40.9 \\
\hline Left & 18 & 27.3 \\
\hline Bilateral & 21 & 31.8 \\
\hline \multicolumn{3}{|c|}{ DSCSA (mm2) } \\
\hline$>100$ & 25 & 37.9 \\
\hline $76-100$ & 15 & 22.7 \\
\hline$<76$ & 26 & 39.4 \\
\hline
\end{tabular}

DSCSA : dural sac cross sectional area

(slightly improved, much improved, no pain) or not (pain not improved or aggravated).

\section{Statistical Analysis}

Age and DSCSA differences were evaluated by independent 2 sample t-test, and differences due to sex were evaluated using the Chi-square test. Correlations between pain relief and DSCSA, age, and sex were evaluated by the Spearman rank correlation test.

\section{Results}

The 66 participants in this study diagnosed with LSS ranged in age from 34 to 85 years of age, with a mean age of 64.2 and consisted of 32 men and 34 women. The levels and site of the affected regions are shown in Table 1. L4/5 was the most frequently implicated region. In 26 of 66 patients (39\%), DSCSA measured less than $76 \mathrm{~mm}^{2}$.

Improvement (including no pain, much improved, and slightly improved) was observed in 49 patients $(74.2 \%)$ and 45 patients $(66.7 \%)$ at 2 weeks and 6 months following the procedure, respectively (Table 2). Two patients had operations due to severe pain during the follow-up period.

The mean DSCSA was $90.8 \mathrm{~mm}^{2}$. The DSCSA of improved and unimproved patients were $91.1 \mathrm{~mm}^{2}$ and $90.0 \mathrm{~mm} 2$, respectively. The minimum DSCSA measured in the improvement participants was $38.0 \mathrm{~mm} 2$. No significant differences were found between the improved 
Table 2. Response after percutaneous adhesiolysis depend on the 5-point patient satisfaction scale

\begin{tabular}{|l|c|c||}
\hline Response & 2 weeks after procedure & 6 months after procedure \\
\hline No pain & $8(12.1 \%)$ & $8(12.1 \%)$ \\
\hline Much improved & $28(42.4 \%)$ & $27(39.4)$ \\
\hline Slightly improved & $13(19.7 \%)$ & $10(15.2 \%)$ \\
\hline No changed & $16(24.2 \%)$ & $17(25.8 \%)$ \\
\hline Aggravated & $1(1.5 \%)$ & $3(4.5 \%)$ \\
\hline Surgery & & $2(3 \%)$ \\
\hline Total & $66(100 \%)$ & $66(100 \%)$ \\
\hline
\end{tabular}

Table 3. Comparison of Age, DSCSA, and Gender between patients with improvement and no improvement at 2 weeks follow-up

\begin{tabular}{|l|c|c|c||}
\hline \multicolumn{2}{|c|}{ Improvement (n=49) } & No improvement (n=17) & P \\
\hline Age (yr) & $65.4 \pm 14.0$ & $60.9 \pm 13.7$ & 0.256 \\
\hline DSCSA (mm2) & $91.1 \pm 33.4$ & $90.0 \pm 33.0$ & 0.898 \\
\hline Gender & $25(78.1 \%)$ & $7(21.9 \%)$ & \\
\hline male & $24(70.6 \%)$ & $10(29.4 \%$ & 0.484 \\
\hline female & & \multicolumn{3}{||}{} \\
\hline
\end{tabular}

Values are means \pm SD. DSCSA: Dural sac cross sectional area

Table 4. Correlation between pain relief and DSCSA, age, gender at 2 weeks and 6 months follow up

\begin{tabular}{|c|c|c|}
\hline & 2 weeks $(n=66)$ & 6 months $(n=64)$ \\
\hline \multicolumn{3}{|l|}{ DSCSA } \\
\hline Coefficientient $(\mathrm{r})$ & -0.07 & -0.09 \\
\hline$P$ & 0.574 & 0.431 \\
\hline \multicolumn{3}{|l|}{ Age } \\
\hline Coefficientient(r) & -0.041 & -0.009 \\
\hline$P$ & 0.747 & 0.942 \\
\hline \multicolumn{3}{|l|}{ Sex } \\
\hline Coefficientient(r) & 0.130 & 0.216 \\
\hline$P$ & 0.672 & 0.082 \\
\hline
\end{tabular}

DSCSA: Dural sac cross sectional area

and unimproved groups in age, sex, and DSCSA (Table 3). In addition, there were no statistically significant correlations between pain relief and DSCSA, age, sex, or the severity of stenosis (Table 4).

\section{Discussion}

The current report demonstrated a reduction in pain of $66 \%$ of LSS participants at 6 months following percutaneous adhesiolysis. We found, however, that there was no correlation between pain relief and DSCSA in participants with central LSS.

LSS typically manifested as a dynamic mechanical compression of the dura and nerve root sheaths of the cauda equina. This can result in hyperemia, venous congestion, and nerve root edema (1). Percutaneous epidural adhesiolysis has been reported to be an effective method in the treatment of degenerative central lumbar stenosis $(12,18,28)$. Manchikanti et al (18) showed pain relief $(\geq 50 \%)$ in $76 \%$ of participants at one year following the procedure. A systematic review found evidence of Level 1 to Level II-1 to support the effectiveness of percutaneous adhesiolysis in the management of chronic low back pain in post-lumbar surgery syndrome (13). The pain relief achieved by percutaneous adhesiolysis may result from the dissolution of the aberrant adhesion, as well as the targeted delivery into the affected site of local anesthetics, steroids, and hypertonic sodium chloride solution injection, although current knowledge is limited regarding the management of back and/or lower extremity pain secondary to spinal stenosis (6). Despite no observable filling defects following the procedure in our study, 17 of 66 participants had no pain relief. We must acknowledge that the pathophysiology of lumbar stenosis is complex, and 
the mechanical compression of nerve root or inflammatory effect is a major factor, but not the only factor involved (4).

The current study found no correlations between pain relief and age, sex, and DSCSA. Our expectation was that the degree of severe LSS would correlate with lower pain relief following the procedure. However, we did not find any difference in DSCSA between participants who experienced improvement and those who did not.

A previous study found no significant difference in the spinal canal dimension between the surgical and the epidural steroid injection group in those who improve after epidural steroid injection versus those that require a decompression after epidural steroid injection (27). Our findings are consistent with this report, indicating that spinal canal dimension is not predictive of the success or failure of epidural steroid injection in patients with spinal stenosis. Thus, uniplanar spinal canal dimensions may not be fully reflective of the pathology of spinal stenosis (27). Another factor underlying inconsistencies between symptoms and the degree of spinal canal stenosis is the use of static images of spinal canal dimensions in what is a dynamic process (3). Likewise, Uden et al (29) found that myelographic stenosis in elderly patients is not always equivalent to a clinical diagnosis of spinal stenosis. Sirvanci et al (3) also demonstrated that patients with severe central stenosis and moderate lateral stenosis show only minimal disability on ODI scores. Consistent with the current work, previous studies have also failed to find a correlation between age, sex, and pain relief (24). Additionally, complex factors including the presence of multiple sites of compression and/or the cephalad/caudad extension of the compression may contribute to whether spinal stenosis is symptomatic (27).

There were several limitations to the present study. Procedure outcome was measured only by the participants' pain scores. There was not a functional outcome measurement or measurement of psychological improvement, medication reduction, the proportion of participants with $50 \%$ pain relief, or improvement in disability status. In addition, multiple level LSS was excluded, although a majority of patients do have more than one level of stenosis. Further studies in patients with multiple level LSS are therefore indicated for the evaluation of percutaneous adhesiolysis in the treatment of LSS.

In conclusion, percutaneous adhesiolysis was effective for the treatment of LSS at a 6-month follow-up period, but participant outcome did not correlate with DSCSA.

\section{References}

1/ Botwin KP, Gruber RD. Lumbar spinal stenosis: Anatomy and pathogenesis. Phys Med Rehabil Clin N Am 2003; 14:115 .

2. Simotas AC, Dorey FJ, Hansraj KK, Cammisa F, Jr. Nonoperative treatment for lumbar spinal stenosis. Clinical and outcome results and a 3-year survivorship analysis. Spine (Phila Pa 1976) 2000; 25:197-203

3. Sirvanci $M$, Bhatia $M$, Ganiyusufoglu KA, Duran C, Tezer M, Ozturk C, Aydogan $\mathrm{M}$, Hamzaoglu A. Degenerative lumbar spinal stenosis: Correlation with Oswestry Disability Index and MR imaging. Eur Spine ] 2008; 17:679-685.

4. Arbit E, Pannullo S. Lumbar stenosis: A clinical review. Clin Orthop Relat Res 2001:137-143.

5. Spivak JM. Degenerative lumbar spinal stenosis. J Bone Joint Surg Am 1998; 80:1053-1066.
6. Manchikanti L, Boswell MV, Singh V, Benyamin RM, Fellows B, Abdi S, Buenaventura RM, Conn A, Datta S, Derby R, Falco FJE, Erhart S, Diwan S, Hayek SM, Helm S, Parr AT, Schultz DM, Smith HS, Wolfer LR, Hirsch JA. Comprehensive evidence-based guidelines for interventional techniques in the management of chronic spinal pain. Pain Physician 2009; 12:699-802.

7. Manchikanti L, Boswell MV, Singh $V$, Derby R, Fellows B, Falco FJE, Datta $S$, Smith HS, Hirsch JA. Comprehensive review of neurophysiologic basis and diagnostic interventions in managing chronic spinal pain. Pain Physician 2009; 12:E71-E120.

8. Manchikanti L, Boswell MV, Datta S, Fellows $B$, Abdi S, Singh V, Benyamin RM, Falco FJE, Helm S, Hayek S, Smith HS. Comprehensive review of therapeutic interventions in managing chronic spinal pain. Pain Physician 2009; 12:E123-E198.

9. Manchikanti L, Cash RA, McManus CD, Pampati V, Fellows B. Fluoroscopic caudal epidural injections with or without steroids in managing pain of lumbar spinal stenosis: One year results of randomized, double-blind, activecontrolled trial. J Spinal Disord 2011; in press.

10. Manchikanti L, Cash KA, McManus CD, Pampati V, Abdi S. Preliminary results of randomized, equivalence trial of fluoroscopic caudal epidural injections in managing chronic low back pain: Part 4. Spinal stenosis. Pain Physician 2008; 11:833-848.

11. Manchikanti L, Singh V, Cash KA, Pampati $V$, Datta $S$. Management of pain of post lumbar surgery syndrome: Oneyear results of a randomized, double double-blind, active controlled trial of fluoroscopic caudal epidural injections. 
Pain Physician 2010; 13:509-521.

12. Manchikanti L, Pampati V, Fellows B, Beyer CD, Damron KS, Cash KA. Effectiveness of percutaneous adhesiolysis with hypertonic saline neurolysis in refractory spinal stenosis. Pain Physician 2001; 4:366-373.

13. Epter RS, Helm S 2nd, Hayek SM, Benyamin RM, Smith HS, Abdi S. Systematic review of percutaneous adhesiolysis and management of chronic low back pain in post lumbar surgery syndrome. Pain Physician 2009; 12:361-378.

14. Hayek SM, Helm S, Benyamin RM, Singh V, Bryce DA, Smith HS. Effectiveness of spinal endoscopic adhesiolysis in post lumbar surgery syndrome: $A$ systematic review. Pain Physician 2009; 12:419-435.

15. Conn A, Buenaventura R, Datta S, Abdi $S$, Diwan S. Systematic review of caudal epidural injections in the management of chronic low back pain. Pain Physician 2009; 12:109-135.

16. Parr AT, Diwan S, Abdi S. Lumbar interlaminar epidural injections in managing chronic low back and lower extremity pain: A systematic review. Pain Physician 2009; 12:163-188.

17. Buenaventura RM, Datta S, Abdi S, Smith HS. Systematic review of therapeutic lumbar transforaminal epidural steroid injections. Pain Physician 2009; 12:233-251.
18. Manchikanti L, Cash KA, McManus CD, Pampati V, Singh V, Benyamin R. The preliminary results of a comparative effectiveness evaluation of adhesiolysis and caudal epidural injections in managing chronic low back pain secondary to spinal stenosis: A randomized, equivalence controlled trial. Pain Physician 2009; 12:E341-E354.

19. Manchikanti L, Singh V, Cash KA, Pampati V, Datta S. A comparative effectiveness evaluation of percutaneous adhesiolysis and epidural steroid injections in managing lumbar post surgery syndrome: A randomized, equivalence controlled trial. Pain Physician 2009; 12:E355-E368.

20. Daffner SD, Wang JC. The pathophysiology and nonsurgical treatment of lumbar spinal stenosis. Instr Course Lect 2009; 58:657-668.

21. Koc Z, Ozcakir S, Sivrioglu K, Gurbet A, Kucukoglu S. Effectiveness of physical therapy and epidural steroid injections in lumbar spinal stenosis. Spine (Phila Pa 1976) 2009; 34:985-989.

22. Delport EG, Cucuzzella AR, Marley JK, Pruitt CM, Fisher JR. Treatment of lumbar spinal stenosis with epidural steroid injections: A retrospective outcome study. Arch Phys Med Rehabil 2004; 85:479-484.

23. Harrast MA. Epidural steroid injections for lumbar spinal stenosis. Curr Rev Musculoskelet Med 2008; 1:32-38.
24. Lee JW, Myung JS, Park KW, Yeom JS, Kim KJ, Kim HJ, Kang HS. Fluoroscopically guided caudal epidural steroid injection for management of degenerative lumbar spinal stenosis: Short-term and long-term results. Skeletal Radiol 2010; 39:691-699.

25. Botwin KP, Gruber RD, Bouchlas CG, Torres-Ramos FM, Sanelli JT, Freeman ED, Slaten WK, Rao S. Fluoroscopically guided lumbar transformational epidural steroid injections in degenerative lumbar stenosis: An outcome study. Am J Phys Med Rehabil 2002; 81:898-905.

26. Athiviraham A, Yen D, Scott C, Soboleski D. Clinical correlation of radiological spinal stenosis after standardization for vertebral body size. Clin Radiol 2007; 62:776-780.

27. Campbell MJ, Carreon LY, Glassman SD, McGinnis MD, Elmlinger BS. Correlation of spinal canal dimensions to efficacy of epidural steroid injection in spinal stenosis. J Spinal Disord Tech 2007; 20:168-171.

28. Manchikanti L, Saini B, Singh V. Spinal endoscopy and lysis of epidural adhesions in the management of chronic low back pain. Pain Physician 2001; 4:240265.

29. Uden A, Johnsson KE, Jonsson K, Pettersson $H$. Myelography in the elderly and the diagnosis of spinal stenosis. Spine (Phila Pa 1976) 1985; 10:171-174. 